\title{
EROSION OF GADOLINIA DOPED EB-PVD TBCs
}

\author{
R. Steenbakker, R.G Wellman and J.R Nicholls \\ School of Industrial and Manufacturing Science \\ Cranfield University, Bedford, \\ MK 43 OAL, UK.
}

\begin{abstract}
Thermal barrier coatings using $8 \mathrm{wt} \%$ yttria partially stabilised zirconia as the top coat have been used in gas turbine engines for a number of decades and is an accepted technology. However, in recent years there has been a drive towards increasing the efficiency of engines which has resulted in the drive towards higher turbine entry temperatures, thus pushing the current materials to their limits, therefore the need to develop coatings with lower thermal conductivities and greater temperature capabilities. One of the proposed solutions is the addition of rare earth oxides to lower the thermal conductivity of the coatings. Gadolinia additions have been shown to significantly reduce the thermal conductivity of EB PVD TBCs, but there are concerns on how such additions affect the impact resistance of the coatings.
\end{abstract}

The aim of this paper is to further the understanding on the effects of dopants on the erosion resistance of EB PVD TBCs by studying the effects of $2 \mathrm{~mol} \% \mathrm{Gd}_{2} \mathrm{O}_{3}$ additions on the room and high temperature erosion resistance of as received and aged EB PVD TBCs. Previously it has been reported that gadolinia additions increased the erosion rate of EB PVD TBCs, this is indeed the case for room temperature erosion, however under high temperature $\left(825^{\circ} \mathrm{C}\right)$ erosion conditions this is not the case and the doped TBCs have a slightly lower erosion rate than the standard YSZ EB PVD TBCs. This has been attributed to a change in the erosion mechanisms that operate at the different temperatures. This change in mechanism was not expected under the impact conditions used and has been attributed to a change in the column diameter, and how this influences the dynamics of particle impaction.

It is proposed that the important factor in determining the predominant erosion mechanism is the ratio between the contact diameter of the impacting particle and the diameter of the columns of the EB PVD coating. This ratio can also be related to the observed reduction in the measured 
nano hardness of EB PVD TBCs as the load increases and the number of columns interacting with the indenter head increases.

Keywords: Erosion, EB PVD TBC, Doped.

\section{Introduction}

Nowadays it is commonly admitted that EB PVD TBCs offer high strain compliance and good erosion resistance compared to APS TBCs therefore EB PVD TBCs mechanical properties are very attractive knowing that erosion is seen as a secondary cause of failure as small ingested particles can cause significant damage to the coating. Unfortunately EB PVD technique also leads to a coating with a higher thermal conductivity hence the challenge was to lower the thermal conductivity of EB-PVD TBCs to match that of plasma sprayed system to provide a coating with excellent thermal properties.

The mechanisms and techniques to further decrease the thermal conductivity of the EB-PVD TBCs by adding rare earth oxides are well documented ${ }^{1-3}$. It has been shown that rare earth oxide additions can significantly lower the thermal conductivity of EB-PVD TBCs and thermal conductivity close to that of APS TBCs has been achieved by doping the coating with 2 mol\% of gadolinia $^{3}$.

A fair amount of work has been published on the erosion of EB-PVD TBCs in the as-received condition under various conditions of temperature, velocity, impact angles and with different types of erodent ${ }^{4-10}$. The erosion mechanisms of EB-PVD TBCs have also been well described by Nicholls, Wellman and Chen et al ${ }^{4 ; 6 ; 8}$, the effect of heat treatments on the properties of TBCs has also been studied ${ }^{11}$ and work has been done on the erosion of aged samples at room temperature. However the authors are not aware of any work published on the erosion of aged EB-PVD TBCs at high temperature.

The purpose of this work was to determine if rare earth additions modified the erosion resistance and mechanisms of the EB-PVD TBCs. If the erosion resistance of doped EB-PVD TBCs were unchanged it would provide a coating with excellent mechanical and thermal properties and doped TBCs would be a material of choice for high pressure turbine blade applications. 


\section{Testing}

For the experiments two types of coatings were used, a standard $\mathrm{ZrO}_{2}-8 \mathrm{wt} \% \mathrm{Y}_{2} \mathrm{O}_{3}$ and a standard YSZ doped with $2 \mathrm{~mol} \%$ of $\mathrm{Gd}_{2} \mathrm{O}_{3}$. The standard YSZ coatings were deposited on alumina substrate and the doped coatings on zirconia and C263 substrate all by EB PVD. In order to determine the effect of ageing on the erosion rate, two different sets of ageing times and temperature were used. Of the four coatings deposited on the alumina substrate one was tested in the as-received condition, two were heat treated during 100 hours at $1100^{\circ} \mathrm{C}$ and the last one was heat treated 24 hours at $1500^{\circ} \mathrm{C}$. Theses samples were used as reference samples. Among the doped samples, two were used in the as-received condition, two were heat treated 100 hours at $1100^{\circ} \mathrm{C}$ and the last two were heat treated 24 hours at $1500^{\circ} \mathrm{C}$. The different types of specimens are listed in the Table $\mathbf{1 .}$

The erosion tests were carried out using alumina particles with a size range between 90-125 $\mu \mathrm{m}$ for an impact angle of $90^{\circ} \mathrm{C}$ and a feed rate of $0.5 \mathrm{~g} / \mathrm{min}$. The samples were tested at room temperature and at $825^{\circ} \mathrm{C}$. The erosion conditions are listed in Table 2. The erosion tests were carried out using the high pressure gas gun erosion rig at Cranfield University, a description of which can be found in a previous publication by Nicholls et al ${ }^{5}$.

\section{Results and Discussion}

\subsection{Erosion at room temperature}

The results are presented graphically in Figure 1. These results show that the erosion rate at normal impact of standard YSZ increases by circa $50 \%$ when the sample is aged 100 hours at $1100^{\circ} \mathrm{C}$, this is consistent with the results published by Wellman et al ${ }^{11}$ who tested the same type of EB-PVD TBCs under the similar conditions. This trend is observed for the doped TBCs with a dramatic increase of the erosion rate for the sample aged 24 hours at $1500^{\circ} \mathrm{C}$. After the first cycle of the erosion run this sample was completely cracked and after the third cycle $(0.38 \mathrm{~g})$ the coating was penetrated. This increase in erosion rate with ageing is linked with sintering: cracks 
can propagate to neighbouring columns as they are sintered together resulting in a greater material loss per impact ${ }^{11}$.

It was also noted that the doped TBCs on the zirconia and C263 substrate have about the same the erosion rates. Moreover these results show that the erosion rate is greater for the doped TBCs for the samples tested in the as-received condition as well as the aged samples. The erosion rate increases by between $70-80 \%$ when the TBC is doped with $\mathrm{Gd}_{2} \mathrm{O}_{3}$. The reasons for the decrease of erosion resistance due to dopant additions remain unknown.

Gadolinia addition is believed to increase the sintering resistance of the coating ${ }^{12}$. If the top views of the doped and standard are compared it can be noticed that for both TBCs when aged 100 hours at $1100^{\circ} \mathrm{C}$ the top of the columns remain pyramidal and it is difficult to differentiate between the aged and the as-received sample. However at higher ageing temperature for the standard TBC there is evidence of columns sintering together, the boundaries between individual columns is less defined and the pyramidal top is smoothed (Figure 2) . On the contrary the doped TBC shows no evidence of sintering and the top of the columns are still pyramidal hence it is difficult to distinguish the sample that has been aged from the as-received sample by looking at the top view micrographs. Sintering is evident in the cross-section micrograph of the doped TBC aged 24 hours at $1500^{\circ} \mathrm{C}$ however it appears that sintering is less pronounced than in the standard TBC. It has been proposed that dopant additions introduce immobile defect clusters reducing the movement of atoms hence increasing the sintering resistance of the coating ${ }^{12}$. On the one hand improvement in sintering resistance due to gadolinia addition means that the columns of doped TBCs should be less sintered and therefore it should be more difficult for the cracks to propagate to the neighbouring columns and this would result in a lower material loss hence a better erosion resistance. On the other hand, due to sintering, the featherlike structure of the columns is smoothed out and it has been shown that these dendrites act as flaws at the column edge hence promoting crack initiation ${ }^{4}$. It is known that sintering tends to smooth these notches and therefore it probably reduces crack initiation from dendrites. Consequently it could be easier to initiate cracks in a doped TBC that has been aged hence lowering the erosion resistance compared to aged standard TBCs.

The Raman spectroscopy clearly shows that the tetragonal phase is stabilised by the gadolinia addition (Figure 3). The tetragonal phase has a better bend strength, thermal shock resistance and fracture toughness than the monoclinic phase ${ }^{13}$ therefore gadolinia addition should provide a coating with better mechanical properties hence better erosion resistance after ageing compared to 
standard TBCs. However the erosion results show that the erosion is higher for the as-received and aged samples therefore phase transformation may not be the major reason for the increase in erosion rates of aged samples or the addition of dopants has a more significant effect on the coating and its erosion resistance

Gadolinia was added to the coating to reduce the thermal conductivity of EB-PVD TBCs. Other work on dopant additions reported extensive cluster dopant segregation ${ }^{14}$. The dopant composition heterogeneity facilitates the formation of defect clusters and nano-phases which can reach sizes between 5 and $100 \mathrm{~nm}$. Moreover, due to its high atomic mass and different lattice parameter compared to YSZ, gadolinia causes local lattice mismatch in the coating. This results in the formation of micro-cavities at the cluster/matrix interface due to lattice mismatch ${ }^{12}$. However these clusters surrounded by cavities can act as stress concentrators and help to initiate cracks in the coating. Furthermore the lattice mismatch also introduces stresses in the coating which can facilitate the formation of cracks around these clusters and "weaken" the coating. It has been proposed that when a particle impacts a column, a region of plastic deformation surrounded by a region of elastic deformation is formed and on unloading, due to the elastic/plastic mismatch stress field, tensile stresses are generated in the column ${ }^{4}$. These stresses will be greater at the edge of the cavities and the critical stress value to initiate and propagate cracks could be reached more easily as it is represented in Figure 4. Stresses due to lattice mismatch and the formation of defect clusters that scatter phonons to reduce the thermal conductivity could be the reason why doped TBCs have a lower erosion resistance at room temperature.

A new erosion mechanism has been observed for the doped sample tested in the as received condition at room temperature and is illustrated in Figure 5. As it can be seen from the micrographs, lateral cracks run parallel to the surface of the coating at different depths. Furthermore cracks do not stop at the column boundaries and propagate across several columns. It looks like "a stage erosion", on impacts a crack at a depth between 10-20 $\mu \mathrm{m}$ is formed and propagates across multiple columns parallel to the surface. Then the layer is removed exposing the underneath layer to the flow of particles and so on. It is worth noticing that cracks can also be observed much deeper in the coating. This particular erosion mechanism was observed for the doped TBCs on both the zirconia and the C263 substrate in the as-received condition. There was no evidence of this type of cracking in the aged samples. Erosion in the aged samples occurs in the same manner as the standard TBC. 
First it was believed that this was due to segregation of gadolinia and that cracks propagated in layers rich in gadolinia. However the EDS elemental mapping revealed no segregation detectable by this method, gadolinia appeared to be uniformly distributed in the coating and there was no region rich in gadolinia at the edge of the cracks.

It is proposed that during initial impact elastic compression waves are induced beneath the impacting particle. The columns are around 3-5 microns in diameter and the alumina particles size is 100 microns therefore a single impact could affect about 20 columns. The compression waves propagate down the columns and at the interface with the TGO they reflect in diffuse tensile waves and propagate back toward the top of the coating. The tensile stresses generated could cause cracks to form from the dendrites at the edge of the columns and extend across the columns. Once the crack is formed it will grow due to the stresses generated by further impacts and this will lead to the spallation of a complete layer of columns. Moreover further impacts will induce compressive waves which could close the crack hence producing another impact which could generate stress waves causing cracks much deeper in the coating.

If the column diameters of the standard and doped TBCs are compared, the doped TBC has much finer columns in the range of 3-5 microns against 6-8 microns for the standard one. From the micrograph Figure 6 it can be seen that the doped TBC has a "needle like" microstructure and the columns seem much more packed altogether. This is due to the fact that gadolinia has a lower melting point compared to zirconia, indeed for gadolinia $\mathrm{T}_{\mathrm{m}}=2420^{\circ} \mathrm{C}$ and for zirconia $\mathrm{T}_{\mathrm{m}}=2700^{\circ} \mathrm{C}$ therefore the global melting point of the doped coating is lower than the melting point of standard YSZ. As the standard and doped coatings were deposited at the same temperature the mobility of the atoms will be greater during the deposition of the doped coating therefore there will be more nucleation on the substrate and this will result in a coating with tightly packed columns with smaller diameters. Consequently the "saw teeth" which give this particular "featherlike" structure to the columns must be closely entangled and this could explain why the cracks can propagate to the neighbouring columns.

\subsection{Erosion at high temperature}

The results are presented graphically in Figure 7. The erosion rate of the standard YSZ aged 24 hours at $1500^{\circ} \mathrm{C}$ was surprisingly low with an erosion rate of $7.4 \mathrm{~g} / \mathrm{kg}$ and was not expected. The 
trend of the erosion results at room temperature indicates that the erosion rate of the standard YSZ aged 24 hours at $1500^{\circ} \mathrm{C}$ should be higher than the erosion rate of the standard YSZ aged 100 hours at $1100^{\circ} \mathrm{C}$, however, when tested at $825^{\circ} \mathrm{C}$ it was found to be four times lower. It can be seen from Figure 8 that the sintering is very different for this sample and it is very difficult to distinguish individual columns. It is believed this loss in columnar microstructure is caused by CMAS effects due to impurities in the alumina substrate. Consequently the erosion rate of this sample is closer to that of bulk zirconia than an aged EB-PVD TBC. This is significantly lower than that observed by Wellman et al in similar test. However, the substrate used was zirconia and not alumina and consequently CMAS did not affect the sintering of the TBC.

The erosion rate of the doped TBCs increases with the ageing temperature exactly like for the test at room temperature, however when comparing the doped and the standard TBCs aged 100 hours at $1100^{\circ} \mathrm{C}$ the erosion resistance of the doped $\mathrm{TBC}$ is better than the standard $\mathrm{TBC}$. At room temperature the opposite behaviour is observed with the standard TBC a lot more erosion resistant than the doped one. If the results at room temperature and high temperature are compared for the doped TBCs it can be noted that the erosion rates are lower when tested at high temperature. Knowing that the velocity of the impacting particles is higher for the test at high temperature the samples tested at high temperature should have a higher erosion rate compared to those tested at room temperature. Moreover the erosion rate of the doped TBC in the as-received conditions at high temperature $(10.5 \mathrm{~g} / \mathrm{kg})$ is also lower than the erosion rate of the standard sample tested at room temperature $(13.1 \mathrm{~g} / \mathrm{kg})$. These "anomalies" have been attributed to changes in the erosion mechanisms.

In their work on Foreign Object Damage (FOD), Wellman et al have clearly identified that plastic deformation can occur during large particle impact in the form of buckling at high temperature ${ }^{8}$. SEM analysis of sectioned samples (Figure 9) revealed that material loss in the doped TBCs eroded at high temperature was via a FOD type II mechanism rather than an erosion (lateral cracking) mechanism. The micrograph Figure 9 shows that at high temperature, due to impacts, the columns of the doped coating buckled almost without cracking. Consequently doped TBC has the ability to plastically deform at high temperature hence absorbing the kinetic energy of the impacting particles. When a particle impacts the coating it decelerates progressively as the columns buckle therefore the damage caused by the impact is reduced, moreover buckling occurred without significant cracking hence reducing the erosion rate of the doped TBC. Further impacts will increase the degree of buckling in the columns and cracks will start to form as shown 
in Figure 10 and it will be followed by material loss. Kink bands were also found in the doped TBCs eroded at high temperature (Figure 11). When the plastic zone penetrates deeply in the coating the stresses generated can be very damaging and plastic deformation can be accompanied with kink bands that initiates around the perimeter of the plastic zone and large-scale delamination can be formed ${ }^{6}$. Buckling occurred in the sample tested in the as received condition and in the one aged 100 hours at $1100^{\circ} \mathrm{C}$ however there was no evidence of buckling in the sample aged 24 hours at $1500^{\circ} \mathrm{C}$. As the erosion rate for this sample is also reduced compared to the test at room temperature it is believed that there was a certain amount of buckling but it was not evident on the micrographs that were examined.

Plastic deformation in the form of densification was also evident on the doped samples tested at high temperature (Figure 12). Successive impacts generate hydrostatic compression in the columns removing porosity by "dynamic hot pressing" hence forming a densified layer ${ }^{6}$. Further impacts induce elastic stress waves building tensile stresses at the interface between the dense layer and the underlying columnar microstructure that can initiate cracks. These cracks can propagate under subsequent impacts causing partial detachment of the dense layer and material removal as it is shown in Figure 12. Plastic deformation in the form of densification or buckling absorbs the energy of the impacting particles therefore significantly reduces cracking and the damage in the coating and increases the erosion resistance of the doped coating at high temperature.

The switch from "Mode I: erosion" for standard TBCs to "Mode III: FOD" for the doped TBCs tested at high temperature is believed to be linked to the finer microstructure observed for doped TBCs and the higher degree of plasticity under the high temperature test conditions. The size of impacting particles being the same, the ratio between the contact foot print of the impact (D) and the column diameter (d) is higher for doped TBCs consequently the load created by impacting particles is shared between a higher number of columns therefore the applied load is accommodated more efficiently than if it was contained within a smaller number of columns. Analyses of a number of samples impacted under various test conditions have shown that for standard YSZ, a D/d ratio less than one results in "Mode I: erosion" while a D/d ratio of about 2 to 10 results in compaction damage and a ratio greater than 10 results in FOD with the associated kink bands, densification and in some cases buckling of the columns. 
The importance of contact area relative to column diameter has also been noted in the micro hardness testing of EB PVD TBCs, where the measured hardness of the columns decreases as the load increases and the indenter interacts with more and more columns. This has been described as the difference in measuring the hardness of the individual column, when the indent is contained within the column, to measuring the hardness of the coating 'as a whole', when the indenter interacts with more than 15 columns. Between these two points is a transition region where neither the coating as a whole nor the individual column hardness is being measured (Figure 13).

\section{Future work}

By decreasing the deposition temperature a doped coating with coarser columns should be produced consequently this would enable one to determine if the plastic deformation observed for the doped TBCs is due to its fine microstructure or other changes in the microstructure due to gadolinia additions.

\section{Conclusion}

The erosion rates found in this research suggested that gadolinia addition has the detrimental effect of lowering the erosion resistance of the coating at room temperature. Dopant addition is associated with the formation of defect clusters and clusters dopant segregation. These clusters, combined with the stresses generated by the lattice mismatch could be responsible for the reduction in erosion resistance of doped EB-PVD TBCs observed at room temperature.

It has also been shown that doped coatings can plastically deform at high temperature in the form of densification and buckling without significant cracking. Such behaviour is advantageous as it reduces the damage caused by the impact and therefore reduces the erosion rates at high temperature. It was found that the doped TBC tested in the as-received condition at high temperature has a higher erosion resistance than the standard sample tested at room temperature highlighting the significant effect of plastic deformation in the reduction of erosion rates. The finer microstructure observed for doped TBCs is believed to be responsible for this change in erosion mechanism. 
A new erosion mechanism has been observed for the doped TBCs tested at room temperature in the as-received condition. Large cracks propagate across a significant number of columns parallel to the surface at various depths in the coating. It is believed that these cracks are caused by elastic stress waves and can propagate to a significant number of columns due to the fact that columns in the doped coating are narrow and tightly packed.

\section{Acknowledgements}

The authors wish to thank the EC for their financial support under the Hipercoat project and Dr J. Nychka (UCSB) for the raman spectroscopy.

\section{Reference List}

1. J. Singh, D. E. Wolfe, and R. Miller. Low thermal conductivity and high reflectance thermal barrier coatings by EB-PVD for high temperature applications. Processing and fabrication of advanced materials XII (October 2003).

2. C.G. Levi. Emerging materials and processes for thermal barrier systems. Current opinion in solid state and materials science 8, 77-91 (2004).

3. J.R. Nicholls , K.J. Lawson, A. Johnstone, and D.S Rickerby. Methods to reduce the thermal conductivity of EB-PVD TBCs. Surface \& coatings technology 383-391 (2002).

4. R.G. Wellman and J.R. Nicholls. Some observations on erosion mechanisms of EB-PVD TBCs. Wear 89-96 (2000).

5. J.R. Nicholls , M.J. Deakin, and D.S. Rickerby. A comparison between the erosion behaviour of thermal spray and electron beam physical vapour deposition thermal barrier coatings. Wear 352-361 (1999).

6. X. Chen et al. Mechanisms governing the high temperature erosion of thermal barrier coatings. Wear 256, 735-746 (2004). 
7. X. Chen et al. Foreign object damage in a thermal barrier system: mechanisms and simulations. Materials Sciences and Engineering A352, 221-231 (2003).

8. R. G. Wellman, M. J. Deakin, and J. R. Nicholls. The effect of TBC morphology on the erosion rate of EB PVD TBCs. Wear 258, 349-356 (2005).

9. W. Tabakoff. Investigation of coatings at high temperature for use in turbomachinery. Surface and coating technology 39/40, 97-115 (1989).

10. J. R. Nicholls, Y. Jaslier, and D. S. Rickerby. Erosion of EB-PVD thermal barrier coatings. Materials at high temperatures 15(1), 15-22.

11. R.G. Wellman and J.R. Nicholls. On the effect of ageing on the erosion of EB-PVD TBCs. Surface \& coatings technology 80-88 (2004).

12. D. Zhu, Y. L. Chen, and A. Miller. Defect clustering and nano-phase structure characterization of multi-component rare earth oxide doped zirconia-yttria thermal barrier coatings. Ceramic engineering and science proceedings 24, 525-534 (2003).

13. U. Schulz. Phase transformation in EB-PVD yttria partially stabilized zirconia thermal barrier coatings during annealing. J. Am. Ceram. Soc. 83(4), 904-910 (2000).

14. J. Singh and D. E. Wolfe. Architecture of thermal barrier coatings produced by electron beam-physical vapor deposition. Journal of materials sciences 37, 3261-3267 (2002). 


\begin{tabular}{cccc}
\hline Sample & Substrate & Coating & Ageing \\
\hline $\mathrm{A}$ & $\mathrm{Al}_{2} \mathrm{O}_{3}$ & Std YSZ & - \\
$\mathrm{B} \& \mathrm{C}$ & $\mathrm{Al}_{2} \mathrm{O}_{3}$ & Std YSZ & $100 \mathrm{~h}$ at $1100^{\circ} \mathrm{C}$ \\
$\mathrm{D}$ & $\mathrm{Al}_{2} \mathrm{O}_{3}$ & Std YSZ & $24 \mathrm{~h}$ at $1500^{\circ} \mathrm{C}$ \\
$\mathrm{E} \& \mathrm{~F}$ & $\mathrm{ZrO}_{2}$ & Doped & - \\
$\mathrm{G} \& \mathrm{H}$ & $\mathrm{ZrO}_{2}$ & Doped & $100 \mathrm{~h}$ at $1100^{\circ} \mathrm{C}$ \\
$\mathrm{I} \& \mathrm{~J}$ & $\mathrm{ZrO}_{2}$ & Doped & $24 \mathrm{~h}$ at $1500^{\circ} \mathrm{C}$ \\
$\mathrm{K} \& \mathrm{~L}$ & $\mathrm{C} 263$ & Doped & - \\
\hline
\end{tabular}

Table 1 : Table of the different samples used for the experiments 


\begin{tabular}{cc}
\hline Erodent & Alumina \\
\hline Impact angle & $90^{\circ}$ \\
\hline Particle size & $90-125 \mu \mathrm{m}$ \\
\hline Velocity & RT: $100 \mathrm{~m} / \mathrm{s}$ HT: $190 \mathrm{~m} / \mathrm{s}$ \\
\hline Feed rate & $0.495 \mathrm{~g} / \mathrm{min}$ \\
\hline Temperature & Room Temperature $: \mathrm{A}, \mathrm{B}, \mathrm{E}, \mathrm{G}, \mathrm{I}$ and $\mathrm{K}$ \\
& $825^{\circ}: \mathrm{C}, \mathrm{D}, \mathrm{F}, \mathrm{H}, \mathrm{J}$ and $\mathrm{L}$ \\
\hline
\end{tabular}

Table 2 : Test conditions 
Steady state $E(\mathrm{~g} / \mathrm{kg})$

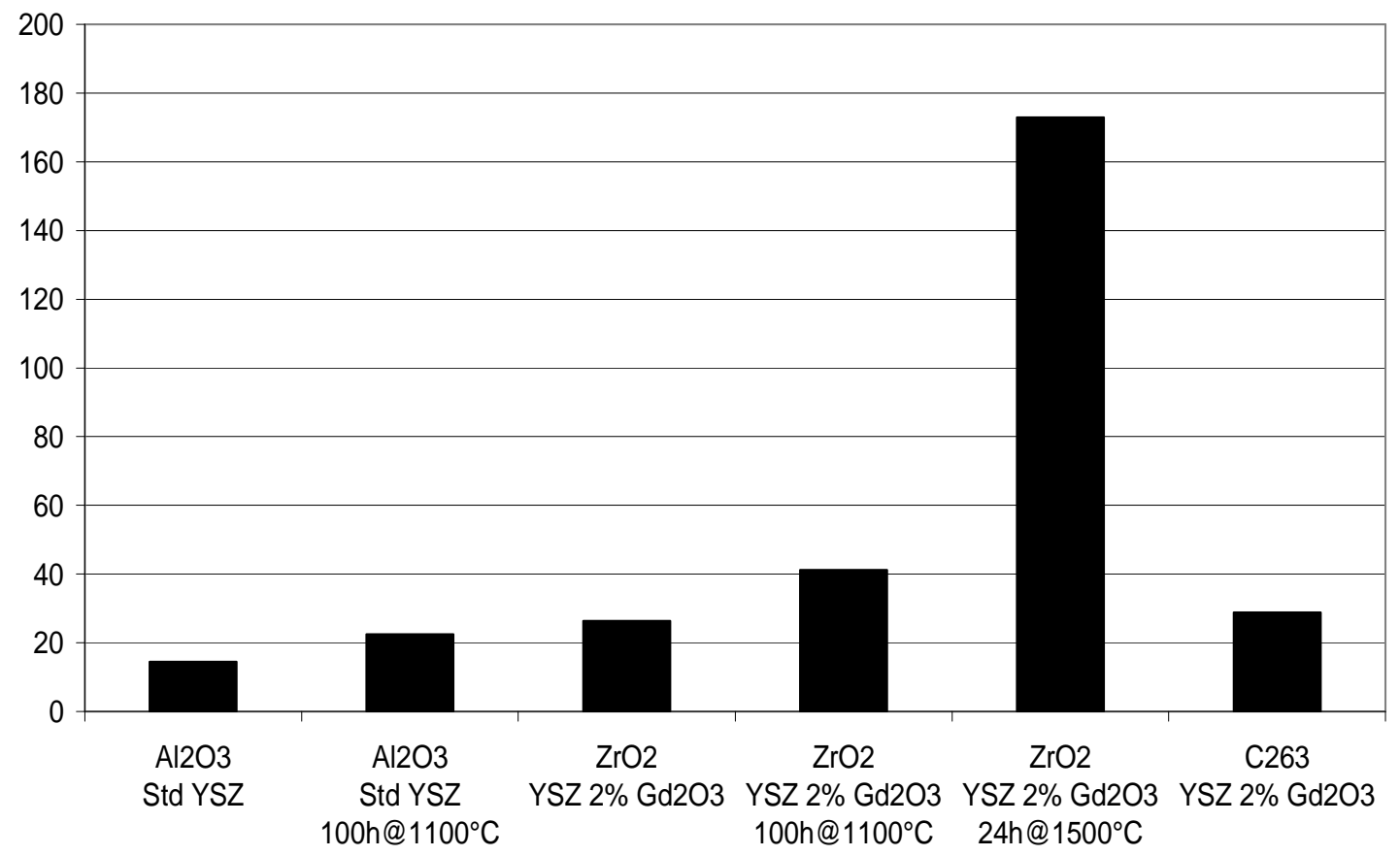

Figure 1 : Erosion rate of TBC at room temperature 


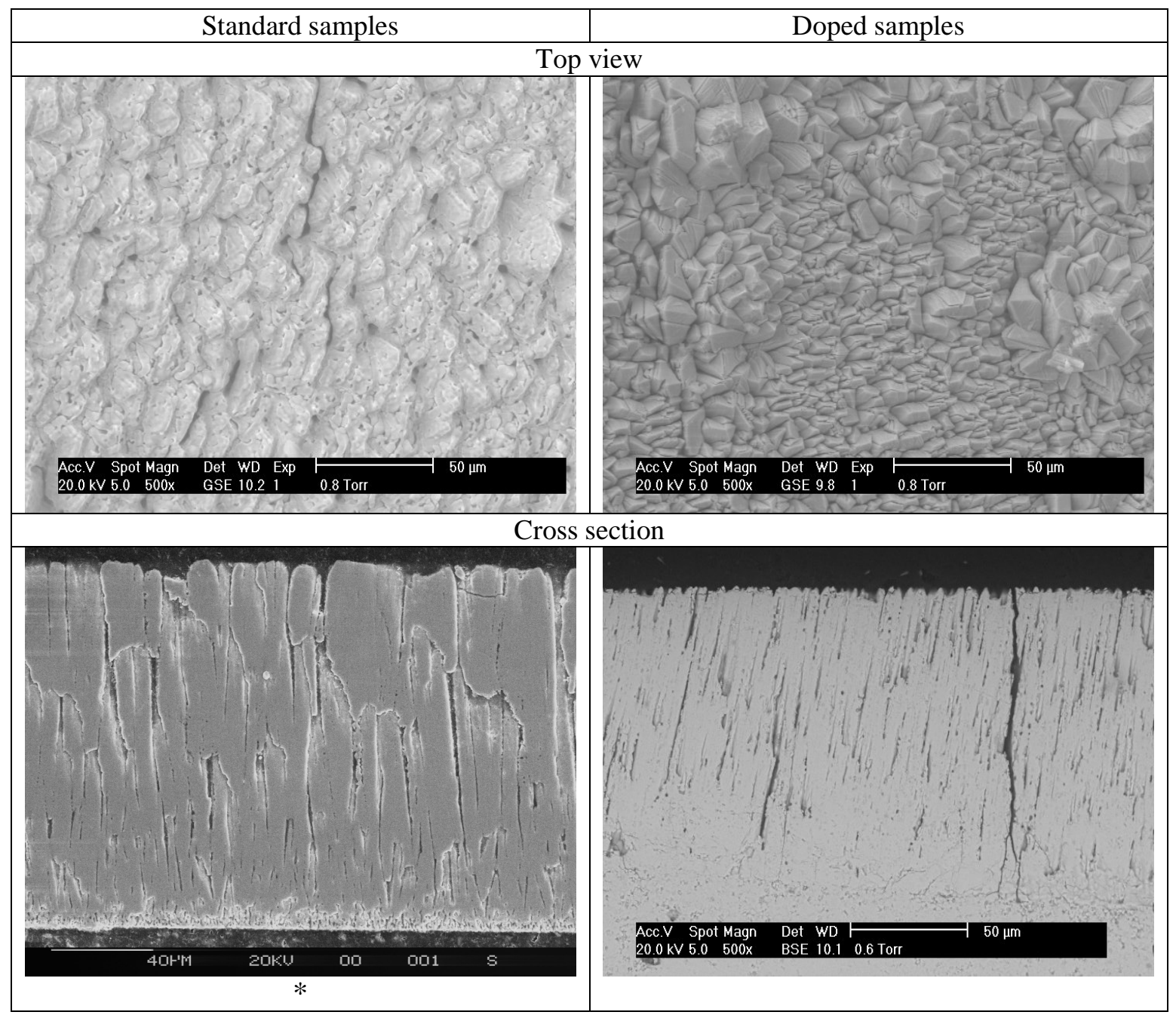

Figure 2 : E-SEM of TBCs aged $24 \mathrm{~h}$ at $1500^{\circ} \mathrm{C}$ used for room temperature erosion, * this micrograph from literature ${ }^{11}$ 


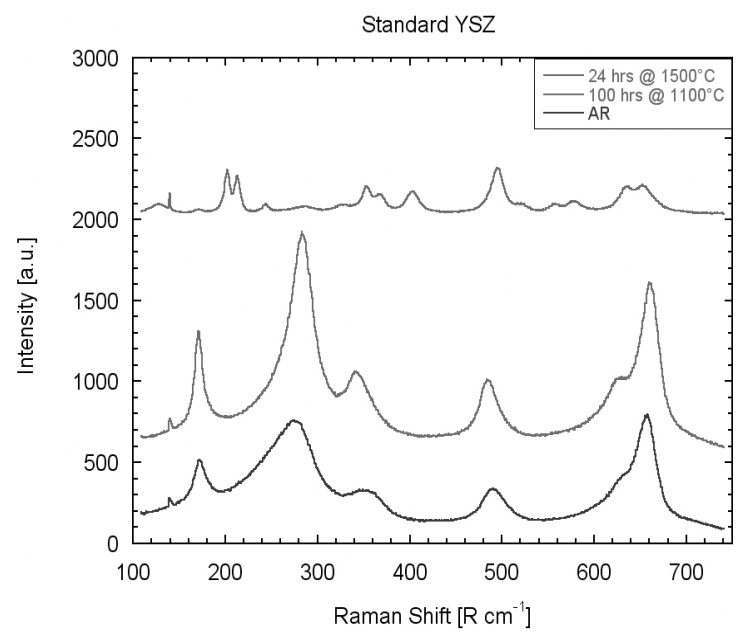

(a)

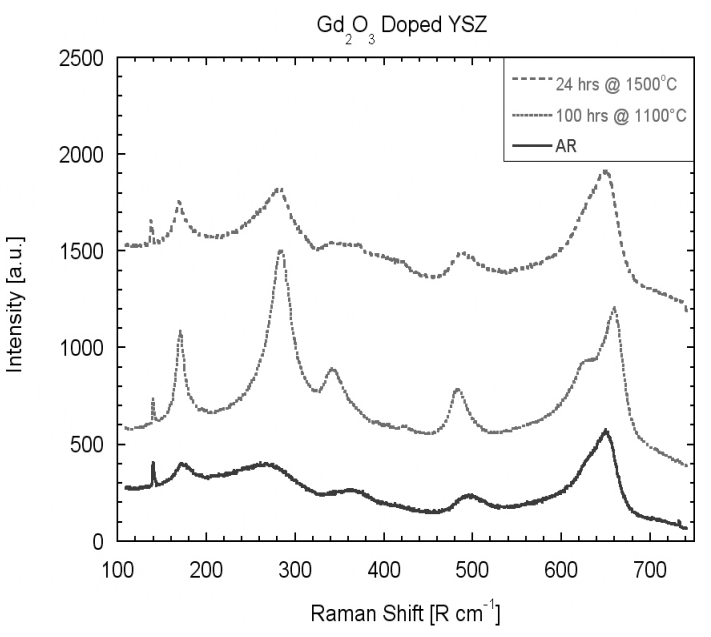

(b)

Figure 3 : Raman spectrographs for different ageing conditions of (a) standard TBC and (b) doped TBC. 


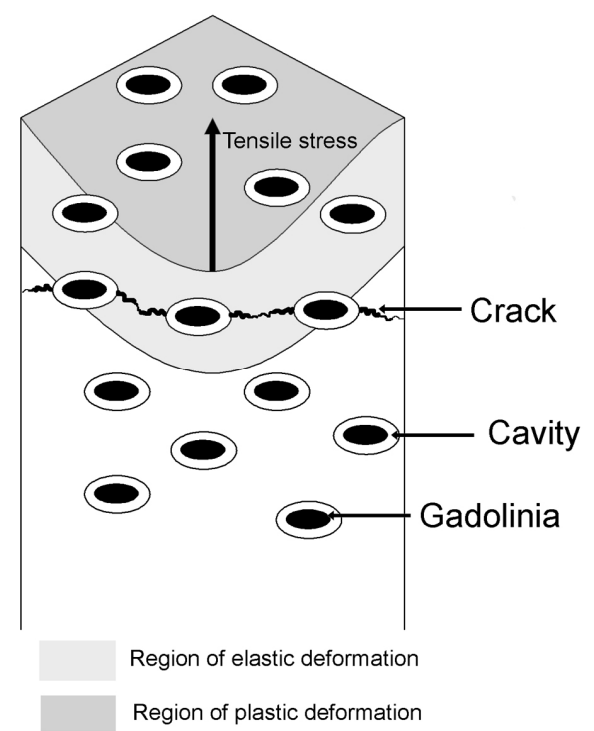

Figure 4 : Crack initiation due to alloying addition. 


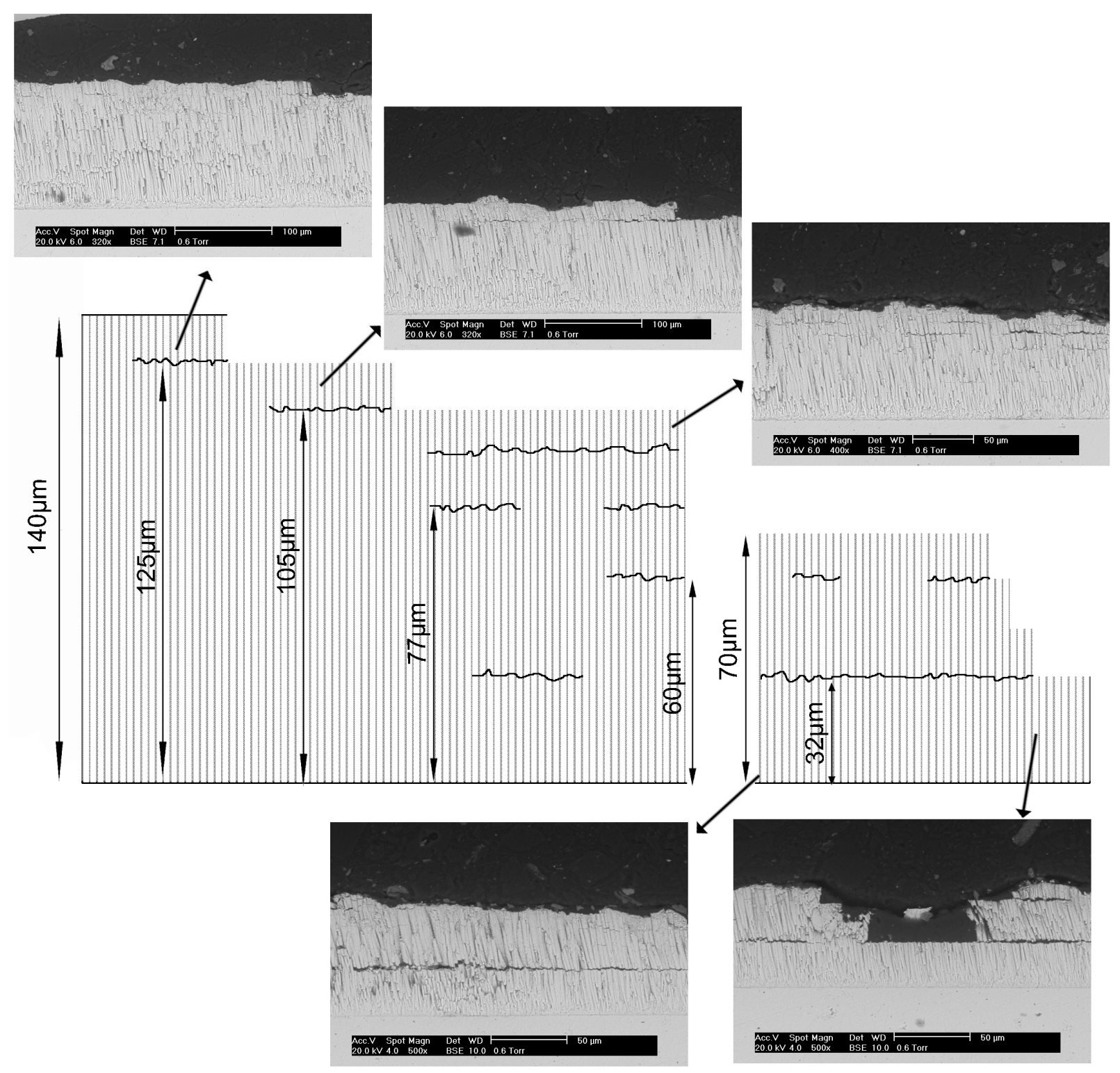

Figure 5 : Schematic representation and micrographs of the new erosion mechanism observed for doped TBCs 


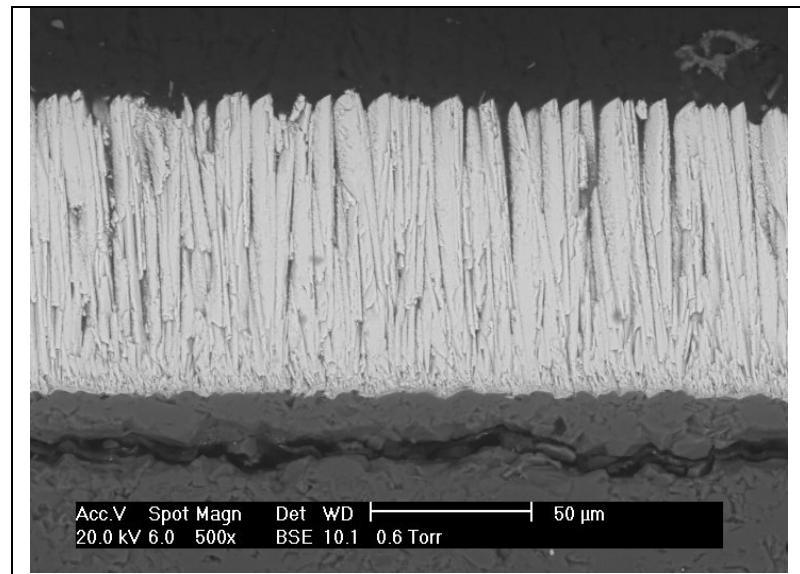

(a)

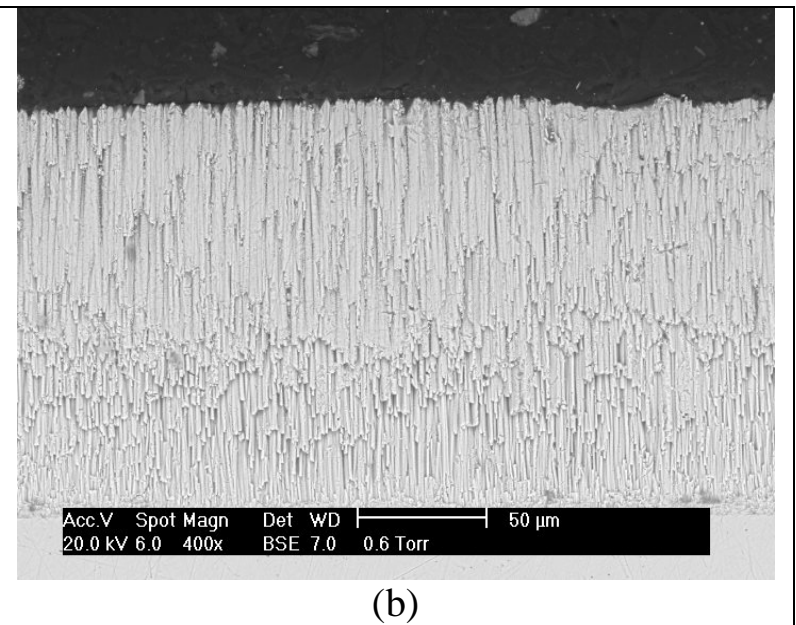

(b)

Figure 6 : (a) Microstructure of a standard EB-PVD TBC, (b) finer microstructure of the doped EB-PVD TBC 


\section{Total E g/kg}

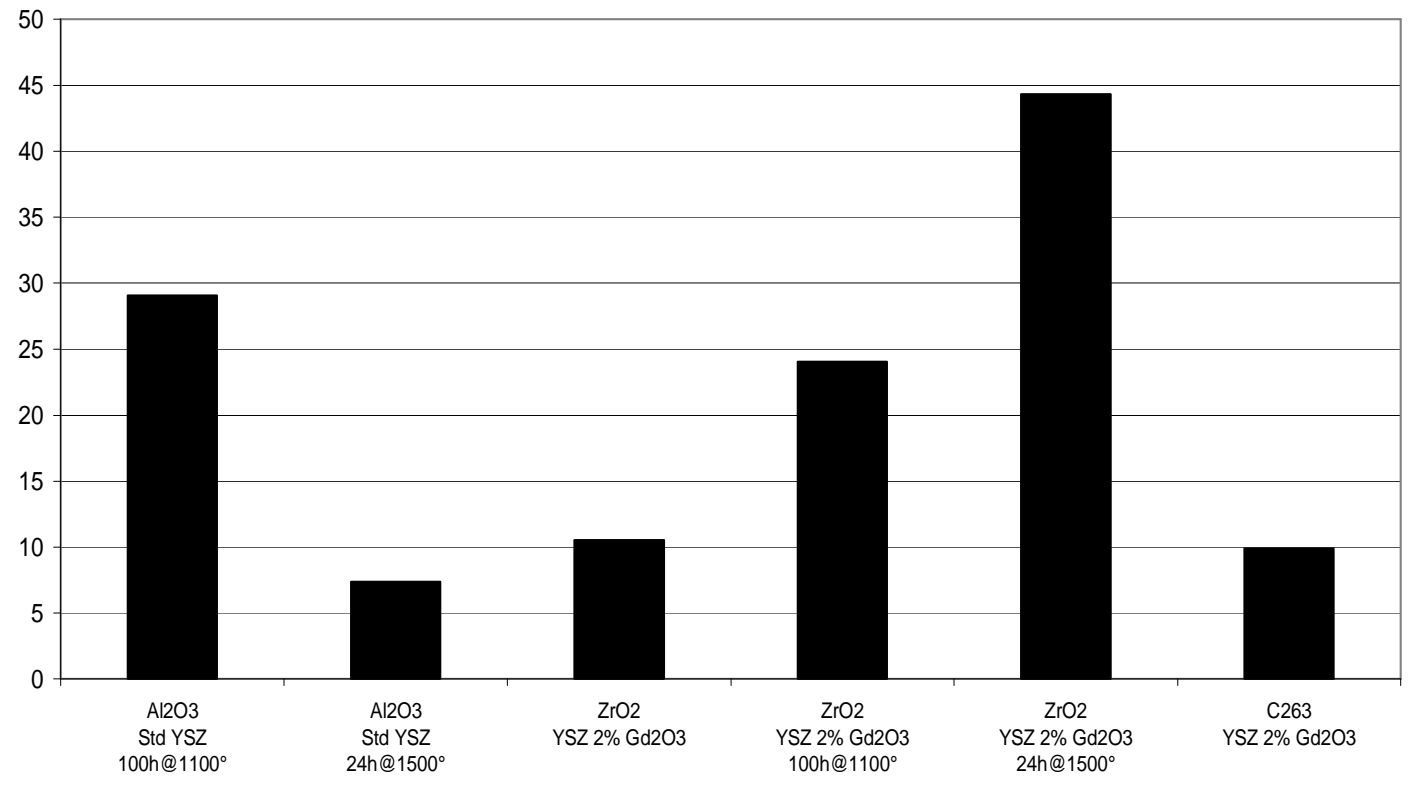

Figure 7 : Erosion rate of TBC at high temperature 


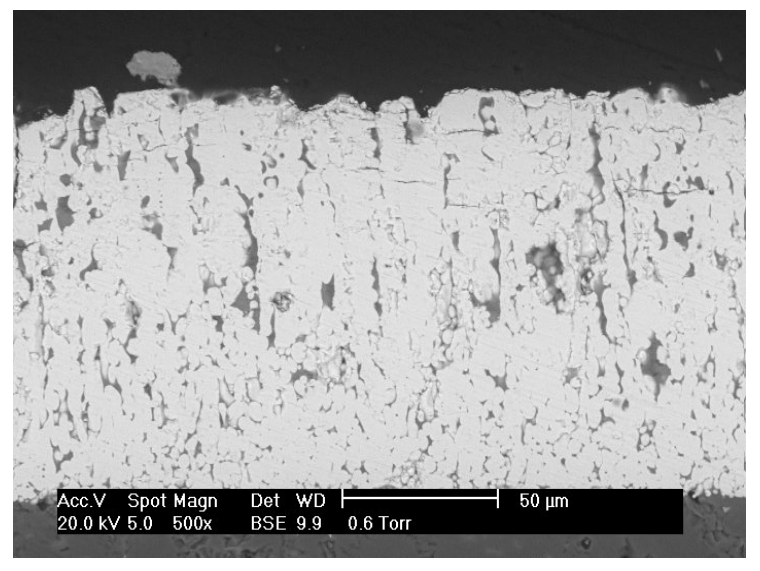

Figure 8 : Micrograph of the standard sample heat treated $24 \mathrm{~h}$ at $1500^{\circ} \mathrm{C}$ tested at high temperature. 


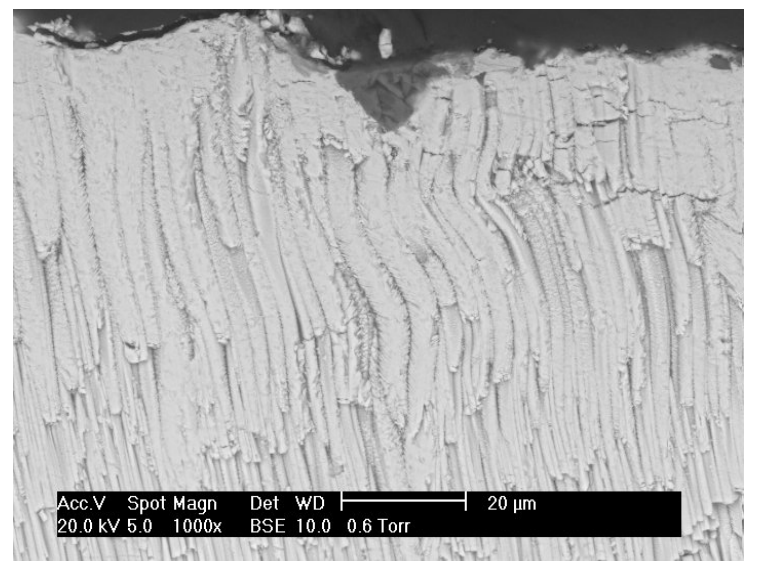

Figure 9 : Buckling in the columns of a doped TBC tested at high temperature 


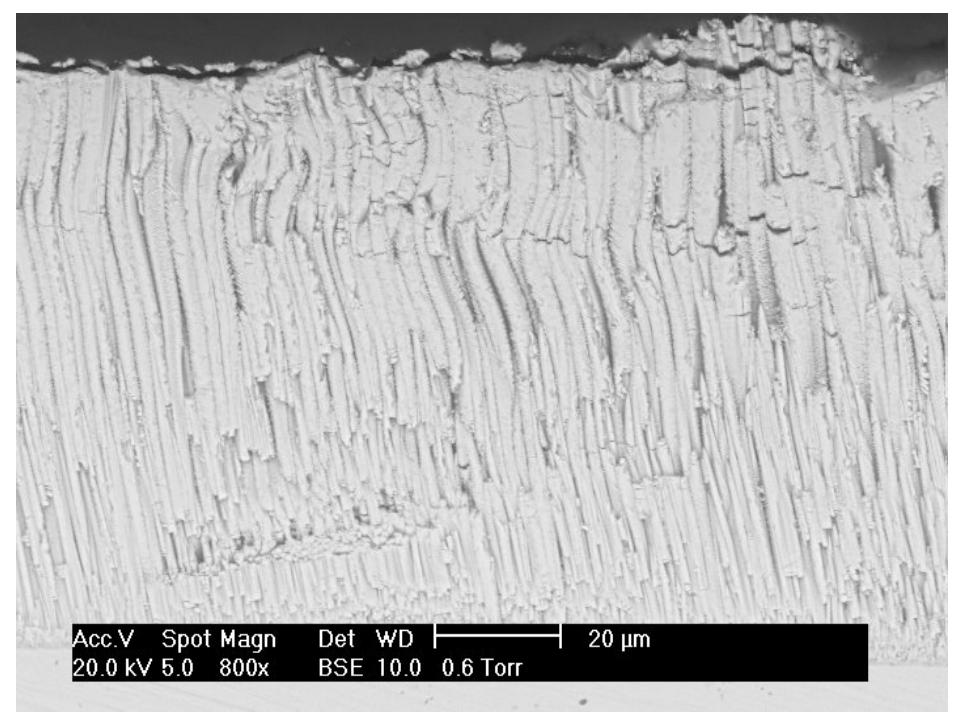

Figure 10 : Cracking of the buckled columns 


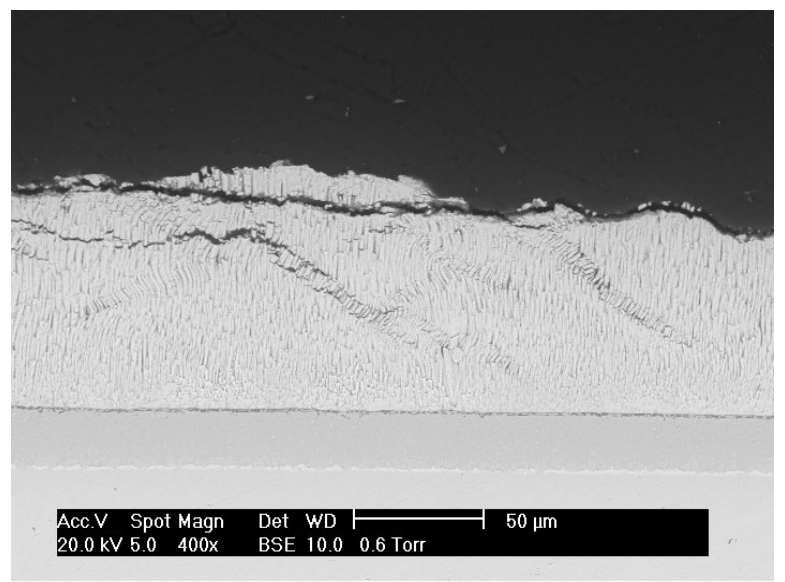

Figure 11 : Kink bands formed in the doped TBCs 


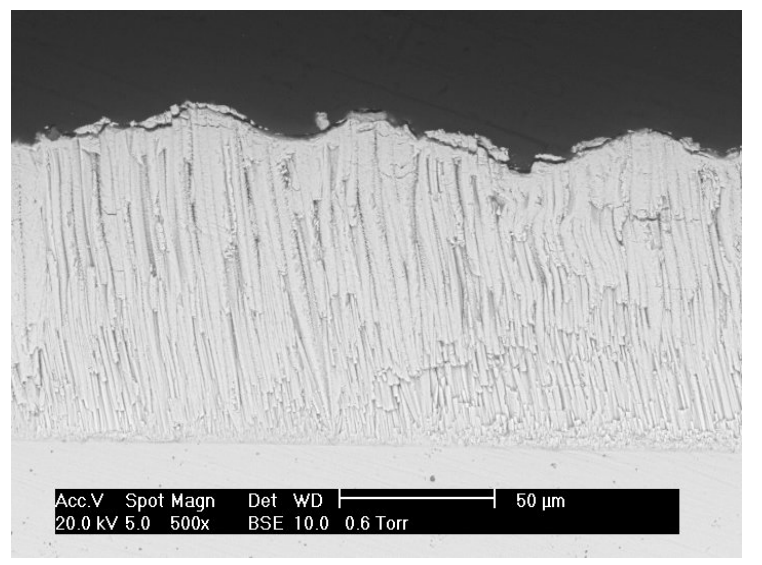

Figure 12 : Densification due to successive impacts 


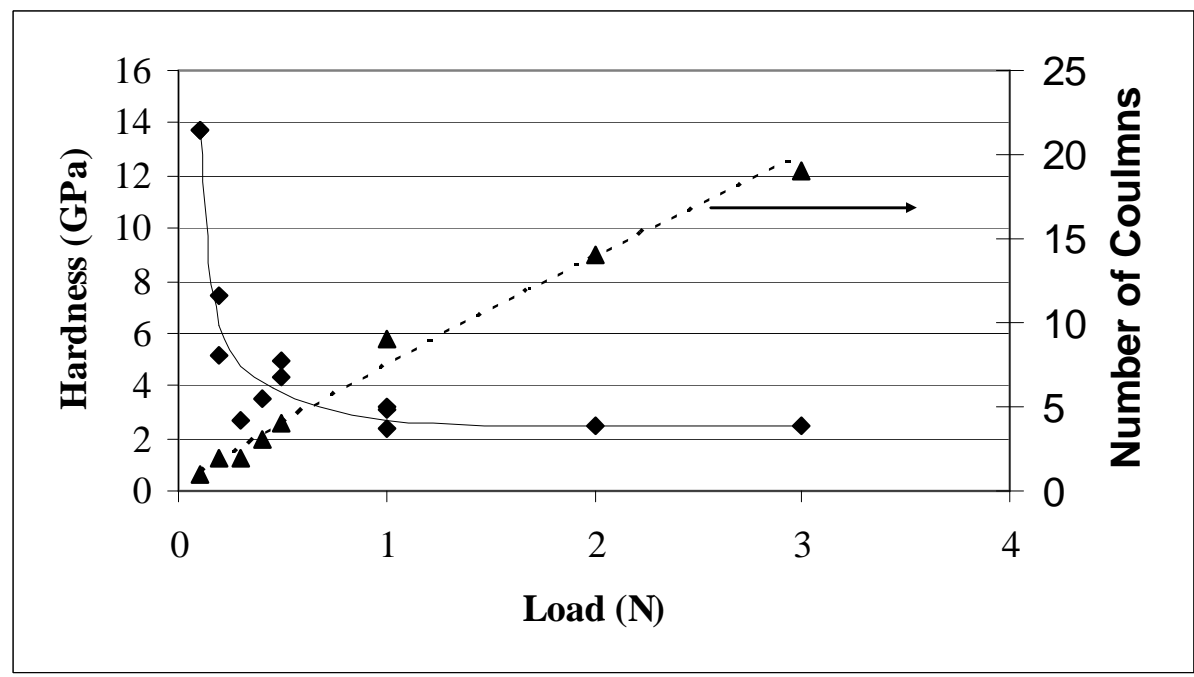

Figure 13 : Hardness as a function of load showing the number of columns interacting with the indenter for the different loads 